\title{
Cardiovascular considerations for anesthesiologists during the COVID-19 pandemic
}

\author{
Naoyuki Hirata ${ }^{1} \odot \cdot$ Michiaki Yamakage $^{1}$
}

Received: 29 June 2020 / Accepted: 25 August 2020 / Published online: 3 September 2020

(C) Japanese Society of Anesthesiologists 2020

\begin{abstract}
The coronavirus disease (COVID-19) pandemic has brought critical challenges to anesthesiologists and perioperative practice. Whereas anesthesiologists may be primarily concerned with airway and respiratory management, the COVID-19 data accumulated to date indicate that primary and/or secondary cardiovascular complications are common. Previous studies have demonstrated that the mortality rate is significantly higher in patients with cardiovascular disease (CVD) than in patients without CVD. Dysregulation of immune function in patients with CVD may be involved in the prognosis of COVID-19 patients. Anesthesia and surgical procedures can modulate the immune system, and some patients undergoing surgery, particularly those undergoing cardiovascular procedures, have CVD. In perioperative management for patients with suspected or diagnosed COVID-19 and those who have recovered from COVID-19, it is important for anesthesiologists to be concerned not only with airway and respiratory management, but also with cardiovascular complications and perioperative circulatory management to control the progression of the disease in patients with COVID-19.
\end{abstract}

Keywords Cardiovascular surgery $\cdot$ Anesthetic management $\cdot$ COVID-19 pandemic

\section{Introduction}

Coronavirus disease 2019 (COVID-19), which is caused by infection with severe acute respiratory syndrome coronavirus 2 (SARS-CoV-2), has become prevalent worldwide. At the time of writing (Aug 5, 2020), the total number of diagnosed patients exceeds $18,000,000$ worldwide, with over 40,000 diagnosed patients in Japan. Due to this pandemic, anesthesiologists and perioperative practice now face critical challenges [1].

The COVID-19 data accumulated to date show that the mortality rate is significantly higher in patients with comorbid cardiovascular disease (CVD) than in patients without CVD [2-4]. Analysis comparing COVID-19 survivors with non-survivors has shown that the case-fatality rate in patients with CVD was $10.5 \%$, while the overall case-fatality

Naoyuki Hirata

naohirata@mac.com

1 Department of Anesthesiology, Sapporo Medical University School of Medicine, South 1, West 16, Chuo-ku, Sapporo, Hokkaido 060-8543, Japan rate was $2.3 \%$ [4]. Moreover, myocardial injury has been observed in patients with COVID-19 and has been reported to be associated with fatal outcomes [3].

Some patients undergoing surgery, particularly those undergoing cardiovascular surgical procedures, have cardiovascular complications. While there is little evidence that SARS-CoV-2 infection during the perioperative period affects postoperative morbidity and mortality in surgical patients, it is important for anesthesiologists to remain aware of cardiovascular complications in patients with COVID-19. This special article is intended to highlight important perioperative cardiovascular considerations during the COVID-19 pandemic.

\section{Epidemiology and prognosis of COVID-19-related cardiovascular disease}

Myocardial injury and cardiomyopathy have been observed in patients with severe COVID-19 [2-4]. The reported incidence of myocardial injury in patients with COVID-19 has ranged from 7.2 to $27.8 \%$ [2, 5-8]. Increases in the levels of cardiac troponin and $\mathrm{N}$-terminal pro-brain natriuretic 
peptide (NT-proBNP) have been shown to be associated with morbidity and mortality $[2,7]$. In previous studies, left ventricular dysfunction, persistent hypotension, myopericarditis, myocarditis, arrhythmia, and heart failure have been observed in COVID-19 patients [5, 9, 10]. Suggested mechanisms by which SARS-CoV-2 induces myocardial injury include direct viral invasion, systemic inflammatory responses, a disorder in the coagulation fibrinolytic system, and pneumonia-induced hypoxia [3]. One case of acute myopericarditis due to COVID-19 has been published [9]. Notably, that patient did not have any pre-existing CVD, nor were any respiratory symptoms observed during the clinical course. However, acute myopericarditis was diagnosed based on the increased levels of NT-proBNP and high-sensitivity troponin $\mathrm{T}$, cardiac magnetic resonance imaging showing increased wall thickness with diffuse hypokinesis (left ventricular ejection fraction of 35\%), and the short tau inversion recovery and T2-mapping sequence showing marked myocardial interstitial edema [9]. Since a previous study showed that RNA of the related virus SARS-CoV was present in 35\% of autopsied human heart samples obtained from patients whose deaths were attributable to SARS [11], direct viral invasion is a feasible mechanism of myocardial injury caused by SARS-CoV-2.

SARS-CoV-2 can induce an excessive inflammatory response that leads to myocardial dysfunction. Septic myocardial dysfunction has been reported in $20-60 \%$ of sepsis patients and is associated with increased mortality [12, 13]. It is known that mitochondrial dysfunction caused by excess inflammatory responses is involved in sepsis-induced myocardial dysfunction $[14,15]$. Inflammatory responses also contribute to hypercoagulation and increased activation of platelets leading to myocardial infarction [16]. Elevated levels of proinflammatory cytokines have been observed in critically ill patients with COVID-19 [6]. However, further studies are required to determine the proportion of COVID19 patients with primary or secondary (due to severe sepsis) myocardial injury or mixed myocardial injury.

\section{Suggested mechanism of COVID-19}

SARS-CoV-2 is considered to be divergent from SARS$\mathrm{CoV}$, which causes severe acute respiratory syndrome [17]. The SARS-CoV spike protein has a strong binding affinity to human angiotensin-converting enzyme 2 (ACE2), and SARS-CoV and SARS-CoV-2 spike proteins show a high degree of homology [18]. Previous studies have demonstrated that SARS-CoV-2 can use the ACE2 protein for cell entry. ACE2 has many important physiological functions and is expressed predominantly in the heart, intestine, kidney, and pulmonary alveolar cells (type II cells), which are the main entry sites for SARS-CoV-2 in humans [19, 20].
ACE2 plays a role in lung protection by reducing the levels of angiotensin II, which is a potent proinflammatory agent in the lungs and can contribute to lung injury. Following entry of SARS-CoV-2 into a cell, ACE2 can be down-regulated [21]. Thus, SARS-CoV-2 binding to ACE2 and the deregulation of ACE2 can contribute to the progression of respiratory impairment [22].

Hypertension is a common chronic condition in surgical patients requiring anesthesia [23-25]. ACE inhibitors and/ or angiotensin-receptor blockers (ARBs) are often used for perioperative blood pressure control in surgical patients with a history of hypertension and other cardiovascular diseases [23]. ACE inhibitors and ARBs may increase the expression of ACE2 [26]. Although up-regulated ACE2 may have antiinflammatory effects in the lung and other organs through the inhibition of angiotensin II, it can also increase viral entry and replication [22]. However, a recent study showed that ACE inhibitors and ARBs are not associated with inhospital mortality in patients with COVID-19 [2].

\section{Risk factors for exacerbation of COVID-19}

Many studies have suggested that pre-existing CVD is associated with exacerbation of COVID-19 [2, 27]. It has been reported that critically ill patients with COVID-19 who required intensive care were more likely to have CVD than non-critically ill patients [27, 28]. Although the mechanistic relationship between pre-existing CVD and the severity of COVID-19 has yet to be fully elucidated, dysregulation of immune function in patients with CVD may be involved in the prognosis of COVID-19 [22]. Previous studies have shown consistent associations of risk factors for CVD (e.g., hypertension, diabetes mellitus, hyperlipidemia, atherosclerosis, and advanced age) with proinflammatory cytokines and cells of the innate and adaptive immune systems [29-33]. Thus, pre-existing CVD is associated with modulated immunologic function and may be an important marker of immunologic impairment for patients with COVID-19 who are at risk of a poor prognosis [22].

Importantly, anesthesia itself and perioperative invasive procedures can modulate the immune system and induce inflammatory responses in patients undergoing surgery [34, 35]. It has been demonstrated that cardiac surgery under cardiopulmonary bypass frequently induces systemic inflammatory response syndrome (SIRS), which is associated with postoperative morbidity and mortality [36]. Immune modulation due to surgical procedures, ischemia-reperfusion injury, and cardiopulmonary bypass are factors that can induce or complement the activation of coagulation or the production of reactive oxygen species by leukocytes and platelets, resulting in SIRS that leads to a poor outcome [37]. 
Several reports of cardiovascular surgery performed in patients with COVID-19 have already been published $[38,39]$. Although evidence showing that cardiovascular surgery under cardiopulmonary bypass worsens the condition of patients with COVID-19 remains limited, one study showed that mortality following thoracic oncologic surgery was higher for patients infected with SARS-CoV-2 than for patients without SARS-CoV-2 [40]. On the basis of the recognized interactions between immunomodulation and inflammatory responses caused by surgical procedures, SARS-CoV-2 infection is likely to exacerbate the condition of perioperative patients, particularly those undergoing highrisk cardiothoracic surgery.

\section{How to manage patients with COVID-19 perioperatively}

When patients with suspected and confirmed COVID-19 undergo surgical procedures, anesthesiologists should be fully committed to preventing cross-infection in the operating room. Several guidelines on anesthetic management in cardiac surgery or emergency procedures for patients with COVID-19 have been developed to help anesthesiologists avoid cross-infection in the operating room [41, 42]. In the perioperative management of such patients, anesthesiologists and intensivists may be primarily concerned with the respiratory condition. However, as described in this article, cardiovascular complications are common, and CVD is associated with a poorer prognosis in patients with COVID-19.

Preoperative cardiac evaluation including measurement of cardiac biomarkers and echocardiography should be considered to detect pre-existing or new-onset CVD in patients with COVID-19 who undergo surgery. During intraoperative and postoperative management of patients with confirmed or suspected myocardial injury, it is desirable to initiate detailed hemodynamic monitoring with arterial catheterization for continuous blood pressure, cardiac output/index, and dynamic variable (e.g., stroke volume variation) monitoring, because inappropriate perioperative hemodynamics can themselves induce myocardial injury [43]. Transesophageal echocardiography (TEE) can help anesthesiologists to evaluate the cardiac condition perioperatively. However, the use of TEE has a risk of spread of SARS-CoV-2 [44]. For TEE in such cases, an appropriate sheath may be able to decrease the cross-infection risk [45].

Primary or secondary CVDs including myocardial injury are risk factors for developing COVID-19. In addition, anesthesia and surgical procedures can modulate immune responses, which may lead to the development of COVID19. With appropriate consideration of the risks and benefits, it is also preferable to postpone or cancel high-risk surgeries that can induce excess inflammatory responses.

\section{Conclusions}

Though the pathophysiology and strategies for control and prevention of COVID-19 prevalence have been suggested, the number of patients with diagnosed COVID-19 continues to increase. Thus, the number of surgical patients with current or past infections with SARS-CoV-2 will increase. As described in this article, SARS-CoV-2 can induce myocardial injury, and preexisting CVD is associated with the progression of COVID-19. Although there is little established evidence showing the effects of anesthesia and surgical procedures on the prognosis of COVID-19 patients, it is important for the anesthesiologist to recognize the COVID19-related cardiovascular concerns to further improve the perioperative management of patients with COVID-19.

The role of anesthesiologists during the COVID-19 pandemic is not only to prevent cross-infection between healthcare workers and surgical patients in the operating room, but also to apply the knowledge gained from the accumulating data to efforts to control the progression of the disease in patients with COVID-19.

Funding The authors have no financial interests in products related to this article.

\section{References}

1. Yamakage M. Anesthesia in times of COVID-19. J Anesth. 2020;25:1-5.

2. Mancia G, Rea F, Ludergnani M, Apolone G, Corrao G. Reninangiotensin-aldosterone system blocker and the risk of COVID19. N Engl J Med. 2020;382:2431-40.

3. Guo T, Fan Y, Chen M, Wu X, Zhang L, He T, Wang H, Wan J, Wang X, Lu Z. Cardiovascular implications of fatal outcomes of patients with coronavirus disease 2019 (COVID19). JAMA Cardiol. 2020. https://doi.org/10.1001/jamacardio .2020.1017(Online ahead of print).

4. Wu Z, McGoogan JM. Characteristics of and important lessons from the coronavirus disease 2019 (COVID-19) outbreak in China: summary of a report of 72,314 cases from the Chinese Center for Disease Control and Prevention. JAMA. 2020. https ://doi.org/10.1001/jama.2020.2648.

5. Wang D, Hu B, Hu C, Zhu F, Liu X, Zhan J, Wang B, Xiang H, Cheng Z, Xiong Y, Zhao Y, Li Y, Wang X, Peng Z. Clinical characteristics of 138 hospitalized patients with 2019 novel coronavirus-infected pneumonia in Wuhan, China. JAMA. 2020;323:1601-9.

6. Huang C, Wang Y, Li X, Ren L, Zhao J, Hu Y, Zhang L, Fan G, Xu J, Gu X, Cheng Z, Yu T, Xia J, Wei Y, Wu W, Xie X, Yin W, Li H, Liu M, Xia Y, Gao H, Guo L, Xie J, Wang G, Jiang R, Gao Z, Jin Q, Wang J, Cao B. Clinical features of patients infected with 2019 novel coronavirus in Wuhan, China. Lancet. 2020;395:497-506.

7. Shi S, Qin M, Shen B, Cai Y, Liu T, Yang F, Gong W, Liu X, Liang J, Zhao Q, Huang H, Yang B, Huang C. Association 
of cardiac injury with mortality in hospitalized patients with COVID-19 in Wuhan, China. JAMA Cardiol. 2020.

8. Yang X, Yu Y, Xu J, Shu H, Xia J, Liu H, Wu Y, Zhang L, Yu Z, Fang M, Yu T, Wang Y, Pan S, Zou X, Yuan S, Shang Y. Clinical course and outcomes of critically ill patients with SARS-CoV-2 pneumonia in Wuhan, China: a single-centered, retrospective, observational study. Lancet Respir Med. 2020;8:475-81.

9. Inciardi RM, Lupi L, Zaccone G, Italia L, Raffo M, Tomasoni D, Cani DS, Cerini M, Farina D, Gavazzi E, Maroldi R, Adamo M, Ammirati E, Sinagra G, Lombardi CM, Metra M. Cardiac involvement in a patient with coronavirus disease 2019 (COVID19). JAMA Cardiol. 2020. https://doi.org/10.1001/jamacardio .2020.1096(Online ahead of print).

10. Hu H, Ma F, Wei X, Fang Y. Coronavirus fulminant myopericarditis saved with glucocorticoid and human immunoglobulin. Eur Heart J. 2020. https://doi.org/10.1093/eurheartj/ehaa190(Online ahead of print).

11. Oudit GY, Kassiri Z, Jiang C, Liu PP, Poutanen SM, Penninger JM, Butany J. SARS-coronavirus modulation of myocardial ACE2 expression and inflammation in patients with SARS. Eur J Clin Investig. 2009;39:618-25.

12. Merx MW, Weber C. Sepsis and the heart. Circulation. 2007;116:793-802.

13. Landesberg G, Gilon D, Meroz Y, Georgieva M, Levin PD, Goodman S, Avidan A, Beeri R, Weissman C, Jaffe AS, Sprung CL. Diastolic dysfunction and mortality in severe sepsis and septic shock. Eur Heart J. 2012;33:895-903.

14. Rudiger A, Singer M. Mechanisms of sepsis-induced cardiac dysfunction. Crit Care Med. 2007;35:1599-608.

15. Kawaguchi R, Hirata N, Yokinaga Y, Hayashi S, Inoue S, Watanabe N, Yamakage M. Nitrite administration improves sepsisinduced myocardial and mitochondrial dysfunction by modulating stress signal responses. J Anesth. 2017;31:885-94.

16. Ma L, Song K, Huang Y. Coronavirus disease-2019 (COVID-19) and cardiovascular complications. J Cardiothorac Vasc Anesth. 2020. https://doi.org/10.1053/j.jvca.2020.04.041(Online ahead of print)

17. Lu R, Zhao X, Li J, Niu P, Yang B, Wu H, Wang W, Song H, Huang B, Zhu N, Bi Y, Ma X, Zhan F, Wang L, Hu T, Zhou H, Hu Z, Zhou W, Zhao L, Chen J, Meng Y, Wang J, Lin Y, Yuan J, Xie Z, Ma J, Liu WJ, Wang D, Xu W, Holmes EC, Gao GF, Wu G, Chen W, Shi W, Tan W. Genomic characteristics and epidemiology of 2019 novel coronavirus: implications for virus origins and receptor binding. Lancet. 2020;395:565-74.

18. Zhang H, Penninger JM, Li Y, Zhong N, Slutsky AS. Angiotensinconverting enzyme 2 (ACE2) as a SARS-CoV-2 receptor: molecular mechanisms and potential therapeutic target. Intensive Care Med. 2020;46:586-90.

19. Zhou P, Yang XL, Wang XG, Hu B, Zhang L, Zhang W, Si HR, Zhu Y, Li B, Huang CL, Chen HD, Chen J, Luo Y, Guo H, Jian RD, Liu MQ, Chen Y, Shen XR, Wang X, Zheng XS, Zhao K, Chen QJ, Deng F, Liu LL, Yan B, Zhan FX, Wang YY, Xiao GF, Shi ZL. A pneumonia outbreak associated with a new coronavirus of probable bat origin. Nature. 2020;579:270-3.

20. Ge XY, Li JL, Yang XL, Chmura AA, Zhu G, Epstein JH, Mazet JK, Hu W, Peng C, Zhang YJ, Luo CM, Tan B, Wang N, Zhu Y, Crameri G, Zhang SY, Wang LF, Daszak D, Shi ZL. Isolation and characterization of a bat SARS-like coronavirus that uses the ACE2 receptor. Nature. 2013;503:535-8.

21. Kuba K, Imai Y, Rao S, Gao H, Guo F, Guan B, Huan Y, Yang P, Zhang Y, Deng W, Bao L, Zhang B, Liu G, Wang Z, Chappell M, Liu Y, Zheng D, Leibbrandt A, Wada T, Slutsky AS, Liu D, Qin $\mathrm{C}$, Jiang C, Penninger JM. A crucial role of angiotensin converting enzyme 2 (ACE2) in SARS coronavirus induced lung injury. Nat Med. 2005;11:875-9.
22. Driggin E, Madhavan MV, Bikdeli B, Chuich T, Laracy J, BiondiZoccai G, Brown TS, Nigoghossian CD, Zidar DA, Haythe J, Brodie D, Beckman JA, Kirtane AJ, Stone GW, Krumholz HM, Parikh SA. Cardiovascular considerations for patients, health care workers, and health systems during the COVID-19 pandemic. J Am Coll Cardiol. 2020;75:2352-71.

23. Roshanov PS, Rochwerg B, Patel A, Salehian O, Duceppe E, Belley-Côté EP, Guyatt GH, Sessler DI, Manach YL, Borges FK, Tandon V, Worster A, Thompson A, Koshy M, Devereaux B, Spencer FA, Sanders RD, Sloan EN, Morley EE, Paul J, Raymer KE, Punthakee Z, Devereaux PJ. Withholding versus continuing angiotensin-converting enzyme inhibitors or angiotensin II receptor blockers before noncardiac surgery: an analysis of the vascular events in noncardiac surgery patients cohort evaluation prospective cohort. Anesthesiology. 2017;126:16-27.

24. Jor O, Maca J, Koutna J, Gemrotova M, Vymazal T, Litschmannova M, Sevcik P, Reimer P, Mikulova V, Trlicova M, Cerny V. Hypotension after induction of general anesthesia: occurrence, risk factors, and therapy. A prospective multicenter observational study. J Anesth. 2018;32:673-80.

25. Ida M, Naito Y, Matsunari Y, Tanaka Y, Inoue S, Kawaguchi M. Prevalence and associated factors of preoperative functional disability in elective surgical patients over 55 years old: a prospective cohort study. J Anesth. 2018;32:381-6.

26. Ferrario CM, Jessup J, Chappell MC, Averill DB, Brosnihan KB, Tallant EA, Diz DI, Gallagher PE. Effect of angiotensinconverting enzyme inhibition and angiotensin II receptor blockers on cardiac angiotensin-converting enzyme 2. Circulation. 2005; 111:2605-10.

27. Li B, Yang J, Zhao F, Zhi L, Wang X, Liu L, Bi Z, Zhao Y. Prevalence and impact of cardiovascular metabolic diseases on COVID-19 in China. Clin Res Cardiol. 2020;109:531-8.

28. Porcheddu R, Serra C, Kelvin D, Kelvin N, Rubino S. Similarity in case fatality rates (CFR) of COVID-19/SARS-COV-2 in Italy and China. J Infect Dev Ctries. 2020;14:125-8.

29. Singh MV, Chapleau MW, Harwani SC, Abboud FM. The Immune system and hypertension. Immunol Res. 2014;59:243-53.

30. Saltiel AR, Olefsky JM. Inflammatory mechanisms linking obesity and metabolic disease. J Clin Investig. 2017;127:1-4.

31. Tall AR, Yvan-Charvet L. Cholesterol, inflammation and innate immunity. Nat Rev Immunol. 2015;15:104-16.

32. Libby P, Ridker PM, Hansson GK. Leducq transatlantic network on atherothrombosis inflammation in atherosclerosis: from pathophysiology to practice. J Am Coll Cardiol. 2009;54:2129-38.

33. Liu WM, van der Zeijst BA, Boog CJ, Soethout EC. Aging and impaired immunity to influenza viruses: implications for vaccine development. Hum Vaccin. 2011;7(Suppl):94-8.

34. Rossint J, Zarbock A. Anesthesia-induced immune modulation. Curr Opin Anaesthesiol. 2019;32:799-805.

35. Boavista BHL, Leme SP, Ferreira CF, Rieken MRP. Immunomodulatory effects of anesthetic agents in perioperative medicine. Minerva Anesthesiol. 2020;86:181-95.

36. Ng KT, Van Paassen J, Langan C, Sarode DP, Arbous MS, Alston RP, Dekkers OM. The efficacy and safety of prophylactic corticosteroids for the prevention of adverse outcomes in patients undergoing heart surgery using cardiopulmonary bypass: a systematic review and meta-analysis of randomized controlled trials. Eur J Cardiothorac Surg. 2020;57:620-7.

37. Warren OJ, Smith AJ, Alexiou C, Rogers PLB, Jawad N, Vincent C, Darzi AW, Athanasiou T. The inflammatory response to cardiopulmonary bypass: part 1-mechanisms of pathogenesis. J Cardiothorac Vasc Anesth. 2009;23:223-31.

38. Martens T, Van de Weygaerde Y, Vermassen J, Malfait T. Acute type A aortic dissection complicated by COVID-19 infection. Ann Thorac Surg. 2020. https://doi.org/10.1016/j.athoracsur .2020.05.001. 
39. He H, Zhao S, Han L, Wang Q, Xia H, Huang X, Yao S, Huang $\mathrm{J}$, Chen X. Anesthetic management of patients undergoing aortic dissection repair with suspected severe acute respiratory syndrome COVID-19 infection. J Cardiothorac Vasc Anesth. 2020;34:1402-5.

40. Peng S, Huang L, Zhao B, Zhou S, Braithwaite I, Zhang N, Fu X. Clinical course of coronavirus disease 2019 in 11 patients after thoracic surgery and challenges in diagnosis. J Thorac Cardiovasc Surg. 2020. https://doi.org/10.1016/j.jtcvs.2020.04.005.

41. He Y, Wei J, Bian J, Buo K, Lu J, Mei W, Ma J, Xia Z, Xu M, Yan F, Yu C, Wang E, Wang W, Zeng N, Wang S, Xu J, Huang Y, Huang J. Chinese Society of Anesthesiology experts consensus on anesthetic management of cardiac surgical patients with suspected or confirmed coronavirus disease 2019. J Cardiothorc Vasc Anesth. 2020;34:1397-401.

42. Zhao S, Ling K, Yan H, Zhong L, Peng X, Yao S, Huang J, Chen $X$. Anesthetic management of patients with COVID-19 infections during emergency procedures. J Cardiothorac Vasc Anesth. 2020;34:1125-31.

43. Salmasi V, Maheshwari K, Yang D, Mascha EJ, Singh A, Sessler DI, Kurz A. Relationship between intraoperative hypotension, defined by either reduction from baseline or absolute thresholds, and acute kidney and myocardial injury after noncardiac surgery: a retrospective cohort analysis. Anesthesiology. 2017;126:47-65.

44. Kirkpatrick JN, Mitchell C, Taub C, Kort S, Hung J, Swaminathan M. ASE statement on protection of patients and echocardiography society providers during the 2019 novel coronavirus outbreak: endorsed by the American College of Cardiology. J Am Coll Cardiol. 2020;75:3078-84.

45. Markin NW, Cawcutt KA, Sayyed SH, Rupp ME, Lisco SJ. Transesophageal echocardiography probe sheath to decrease provider and environment contamination. Anesthesiology. 2020;133:475-7.

Publisher's Note Springer Nature remains neutral with regard to jurisdictional claims in published maps and institutional affiliations. 